\title{
Effect of Immersion Time and Temperature on Corrosion Behaviour of Nanocrystalline Al-Fe-Cr Alloy
}

\author{
Muneer Baig ${ }^{1}$, , Hany Rizk Ammar ${ }^{2,3}$, Asiful Hossain Seikh ${ }^{1^{*}}$, Mohammad Asif Alam ${ }^{1}$, \\ Nabeel H. Alharthi, ${ }^{1,4}$ \\ ${ }^{1}$ AMI-Center of Excellence for Research in Engineering Material, King Saud University, Riyadh, KSA \\ ${ }^{2}$ Mechanical Engineering Department, College of Engineering, Qassim University, Buraidah, \\ Kingdom of Saudi Arabia \\ ${ }^{3}$ Metallurgical and Materials Engineering Department, Faculty of Petroleum and Mining Engineering, \\ Suez University, Suez, Egypt \\ ${ }^{4}$ Mechanical Engineering Department, College of Engineering, King Saud University, Riyadh, \\ Kingdom of Saudi Arabia \\ *E-mail: aseikh@ksu.edu.sa
}

doi: $10.20964 / 2017.04 .14$

Received: 4 January 2017 / Accepted: 16 February 2017 / Published: 12 March 2017

The corrosion behavior of Al-10wt. $\% \mathrm{Fe}-5 \mathrm{wt} . \% \mathrm{Cr}$ nanocrystalline aluminium alloy was studied by cyclic potentiodynamic polarization (CPP) and electrochemical impedance spectroscopy (EIS) methods. The nanocrystalline bulk alloy used in this investigation was fabricated by processed metallic powder via mechanical alloying (MA) technique followed by compaction and sintering in a high frequency induction heat sintering (HFIHS) system. The corrosion behavior of the alloy was tested in a $3.5 \% \mathrm{NaCl}$ solution for different immersion time and temperatures. The outcomes showed that the developed alloy possess good resistance to uniform corrosion at all temperatures. It is also found that increasing the immersion time, results in moving the corrosion potential $\left(E_{\text {corr }}\right)$ towards a higher negative value that leads to decrease the corrosion current $\left(j_{\text {corr }}\right)$ and consequently increase the corrosion resistance $\left(\mathrm{R}_{\mathrm{p}}\right)$ of the alloy.

Keywords: Nanocrystalline aluminium alloy, mechanical alloying, corrosion, polarization, EIS.

\section{$\underline{\text { FULL TEXT }}$}

(C) 2017 The Authors. Published by ESG (www.electrochemsci.org). This article is an open access article distributed under the terms and conditions of the Creative Commons Attribution license (http://creativecommons.org/licenses/by/4.0/). 